\title{
Blasons et contreblasons anatomiques \\ du corps fémenin: cuatro ejemplos de traducción al castellano
}

\author{
RAfael García de MESA \& José Reyes de la RosA \\ Universidad de Córdoba
}

Resumen: Los "blasones y contrablasones" de los que presentamos cuatro ejemplos de traducción al español, constituyen un tiempo de poesía frecuentemente marginada en la producción poética francesa del s. XVI. Se trata de una poesía erótica y procaz dentro de la tradición popular gauloise, recuperada en la segunda mitad del s. XX. En este artículo, además de la traducción, pretendemos acercarnos a esta poesía erótica que revela no pocas coincidencias estético-culturales con la poesía española de la época.

Abstract: The "shields of arms and countershields of arms" are cases of marginal poetry in French during the $16^{\text {th }}$ century. We present here four examples of them translated into Spanish. It is an erotic and daring poetry in the popular tradition gauloise which has been revitalized in the second half of the $20^{\text {th }}$ century. In addition to the translation we attempt $n$ this article to face the erotic poetry reveals quite a few aethetic-cultural coincidences with the Spanish poetry of that time.

Palabras clave: Poesía erótica. Blasón. Contrablasón. Estética.

Key words: Erotic Poetry. Shields of arms. Countershields of arms. Aesthetics.

$$
\infty
$$

Toda traducción de poesía plantea una serie de problemas específicos ligados a la singularidad de la expresión poética, que se caracteriza, fundamentalmente, por el valor connotativo de su lenguaje y la función estéticosimbólica de su discurso.

La Historia de la traducción y los estudios traductológicos, abundantes especialmente en los últimos cuarenta años, nos han dado cuenta de la complejidad del problema a través de reflexiones teóricas y demostraciones prácticas que no hacen sino corroborar el carácter polémico de un debate interminable donde se afrontan posiciones tan extremas como las que niegan toda posibilidad de traducir poesía ( G. Mounin: 1963) y las que admiten la viabilidad de traducción de cualquier texto poético (O. Paz: 1971). 
Desde Cicerón hasta Paul Valéry, pasando por San Jerónimo, Du Bellay o Schleiermacher, muchos han sido los esfuerzos de teorizadores y críticos de la actividad traductora encaminados a esbozar los fundamentos de una auténtica traductología que el siglo $\mathrm{XX}$, especialmente en su segunda mitad, ha querido cimentar desde nuevas perspectivas y campos de conocimiento del lenguaje y el habla (lingüística textual, teoría de la comunicación, hermenéutica etc. ).

Pero todo este impulso de siglos, que ha traído el reconocimiento, aún reciente, de la traducción como disciplina de estudio y la creación de escuelas y facultades cuyo objetivo es la preparación teórica y practica de técnicos traductores, no ha servido, sin embargo, para que esta actividad humanística alcance el estatuto científico que gozan otras disciplinas del campo de las Humanidades. Lejos de ello, muchas de las discusiones de los tratadistas parecen aún centradas en discernir si la traducción es un arte o una ciencia. Una cuestión que Octavio Paz zanjaba hace ya más de treinta años afirmando que "no hay ni puede haber una ciencia de la traducción, aunque ésta puede y debe estudiarse científicamente" $(1971,18)$. $\mathrm{Y}$ en efecto, hoy resulta evidente la interdisciplinaridad en la que se mueve el hecho traductológico y la necesidad que tiene la traducción de auxiliarse de diversas disciplinas, no sólo de las ya tradicionales ligadas a la filología, sino también de otras como la sociología, la antropología, la psicología o la literatura comparada, para mejorar sus resultados.

Otros puntos de la controversia que sigue oponiendo a los estudiosos de la traducción en los tiempos actuales, se refieren a la cuestión de "los universales lingüísticos de la traducción" (E. Coseriu, 1979), que enfrentaría a "universalistas" y "relativistas", así como a los diferentes tipos de traducción y los procedimientos que se consideran más adecuados. La Escuela Norteamericana de Nida y Taber, la Escuela Fraco-Canadiense de Vilnay y Darbelnet, los trabajos de Theodore Savory y los recientes estudios de Esteban Torre o Teodoro Sáez de Hermosilla en España, son algunos ejemplos, sobradamente conocidos, de un debate siempre actual y renovado.

Pero, volviendo al objeto que nos ocupa, la traducción específica de poesía, o más concretamente a la traducción de la expresión poética versificada, el debate se intensifica y la cosa se complica hasta tal punto que, como señala Esteban Torre, " todos los expertos están de acuerdo en que la adecuada traducción de un poema es algo realmente imposible" $(1994,205)$. Esta afirmación, que no niega la posibilidad e incluso la necesidad de traducir poemas, no deja, sin embargo, muy claro lo que se entiende por "adecuada traducción", algo que no quiere decir lo mismo para todos los tratadistas, algunos de los cuales han realizado "adecuadas" y felices traducciones poéticas (Octavio Paz o el propio Torres), en las que se logra, en algunos casos, esa relación entre sonido y sentido que, al parecer, resulta lo más difícil de una traducción que se precie de ser "poética". 
Ahora bien, en este punto conviene tener en cuenta lo que plantea Sáez de Hermosilla, que no entiende "por qué en poesía hay que respetar, copiar la sustancia del signo ni que esas recurrencias (rima, sonoridad) tengan que ser esenciales específicamente al hecho poético, sino que lo único posible y razonable es recrear la totalidad de la impresión estético-lúdica" (1986, 44). El traductólogo nos precisa acertadamente que "la poesía no se identifica con el verso ni con la métrica" $(1988,44)$. Un planteamiento que coincide con el de Octavio Paz cuando, rememorando a Valéry, nos recordaba que "el ideal de traducción poética consiste en producir con medios diferentes efectos análogos" $(1971,23)$.

Efectos estéticos que nada tienen que ver, desde luego, con el mimetismo fónico, con la equivalencia métrica, ni con el respeto de la rima, aspectos todos ellos puramente formales que pertenecen al ámbito del verso y no forzosamente de la propia poesía. Aunque, también habría que considerar, como bien apunta Torre, que "en la traducción de un texto poético escrito en verso, la forma de la expresión está indisolublemente unida a la forma del contenido" $(1994,207)$, por lo que, precisa a continuación, "el contenido morfosintáctico y semántico del poema viene a constituir el hilo conductor de la expresión rítmica" $(1994,207)$.

El propio Torre nos da, desde su perspectiva traductológica, buena prueba de una práctica traductora capaz de recrear fondo y forma, contenido y expresión, con poemas de autores tan significativos como Baudelaire y Verlaine $(1994,210)$. Unos ejemplos de traducción que se acercan bastante a ese registro rítmico del poema que propugna Sáez de Hermosilla como ideal al que debe tender toda traducción poética, entendiendo por ritmo esa "estructuración específica del sentido con todos los aspectos que conlleva: lengua, cultura, significación, estilo, metro, fonética y simbolismo" $(1986,44)$.

Pues bien, partiendo de estas breves consideraciones teóricas, que sólo pretenden situarnos en lo que a nuestro modo de entender constituye el núcleo de la problemática traductora, y desde la perspectiva de una traducción que intenta recrear el poema en ese ritmo profundo capaz de aprehender todos esos componentes que conforman su realidad estético-lúdica, queremos acercarnos a los Blasons et contrablasons anatomiques du corps féminin, de los que vamos a ofrecer cuatro ejemplos de traducción poética.

Nuestra traducción se refiere a un tipo de poesía que ha estado durante mucho tiempo, si no completamente olvidada, sí reducida a la condición de un producto marginal, casi anecdótico, dentro de la producción poética del siglo XVI en Francia. Una poesía que nos revela, sin embargo, algunos de los rasgos más representativos de la literatura de la primera mitad del siglo XVI francés, al mismo tiempo que pone de manifiesto el vigor y la riqueza de un género perfectamente fijado y codificado, cuyo valor y repercusión literarios van más allá del reducido espacio que la crítica y la historia de la literatura le han concedido. 
En España no encontramos un equivalente del género como tal y no existen pruebas de que los blasones se conocieran, al no existir ni traducciones ni referencias de los poetas y tratadistas españoles de la época a esta modalidad poética francesa. Aunque, como tendremos ocasión de comprobar, la literatura española de los siglos XVI y XVII presenta no pocos ejemplos de correspondencias en la obra de autores como Góngora o, sobre todo, Quevedo en su vertiente más satírica, que responden al mismo espíritu blasonneur de los poetas franceses y utilizan los mismos códigos estéticos y culturales.

Los Blasones anatómicos del cuerpo femenino constituyen una poesía esencialmente "pictórica", que ilustra perfectamente esa "dominante visual" que rige según Roman Jakobson todo el arte del Renacimiento:

"Il est évident que, dans l'art de la Renaissance, la dominante, le summun des critères esthétiques de l'époque, était représenté par les arts visuels. Les autres arts étaient tous orientés vers les arts visuels et se situaient dans l'echelle des valeurs selon leur éloignement ou leur proximité de ces derniers" $(1977,79)$.

Este visualismo pictórico que se manifestaría, según el reconocido lingüista, por la sumisión de la estética literaria a las artes pláticas, especialmente a la pintura, tiene uno de sus mejores exponentes en esta poesía descriptiva y laudatoria del cuerpo femenino. En un tiempo en el que la pintura reina, ciertamente, sobre todas las demás artes, el blason es fiel exponente del espíritu manierista de la Escuela de Fontainebleau, que tiene en el cuerpo femenino su objeto supremo de culto y veneración y hace del desnudo una práctica de la representación insinuante y lasciva, de erotismo ambiguo, en el que se reconocen los mejores poetas blasonneurs.

Se trata, por lo tanto, de una poesía erótica, que sigue en muchos casos la vena sensualista y procaz de la tradición popular gauloise y se apoya, todavía, en los usos y procedimientos formales de la vieja escuela de los rhétoriqueurs, pero que asienta su estética, de acuerdo con la teoría de Jakobson, en esas correlaciones formales y cromáticas que generan la metáfora y sustentan la descripción en la poesía renacentista.

El rasgo identificativo más relevante del blasón, el desmembramiento poético del cuerpo femenino, que E. Fernández atribuye a la tradición poética petrarquista $(2001,30)$, nos orienta hacia alguna de sus fuentes, aunque, como veremos a continuación, el origen más inmediato de los blasones franceses haya que buscarlo más que en el verso de Petrarca en los populares strambotti, pequeñas composiciones de ocho versos con las que los poetas italianos del renacimiento desnudan y fragmentan de manera obsesiva el cuerpo de la mujer ( $P$. Guinard, 1982). Porque a diferencia del blasón de Petrarca en su Rime sparse, que 
suele incluir en un mismo poema varias partes del cuerpo femenino, los blasons anatomiques $d u$ corps féminin singularizan alguna parte del cuerpo y raras veces se relaciona con alguna otra. Un afán extremado de desmembrar el cuerpo de la mujer que está intimamente relacionado con las nuevas formas de la Medicina en el estudio del cuerpo humano mediante la disección de cadáveres, práctica que invade Europa, especialmente tras la publicacicnes de Andreas Vesalio (E. Fernánde, 32 ).

La historia del nacimiento, evolución y recepción de los blasones del cuerpo femenino, que sólo esbozaremos aquí, tiene su protagonista de excepción, Clement Marot, y un primer capítulo bien conocido, quizás algo exagerado y novelesco, que merece la pena recordar.

Corría el otoño de 1535 y en la pequeña corte italiana de Ferrara, donde vive exiliado el poeta calvinista, tiene lugar un curioso certamen poético auspiciado por la duquesa Renée de Francia, la protectora de Marot, e impulsado por el propio poeta: se trata de premiar el mejor poema "blasonador" del cuerpo femenino. Entre los numerosos poetas que se apresuran a participar destacan los nombres de Mellin de Saint-Gelais, Maclou de la Haye, Victor Brodeau, Jacques Peletier du Man, Bonaventure Des Periers y Maurice Scève, que fue precisamente el vencedor del concurso con su blasón Le Sourcil:

Pocos meses antes, Marot había enviado a sus amigos de la Corte de Francisco $\mathrm{I}^{\circ}$ un epigrama lleno de gracia y sensualidad, Le beau Tetin, a imitación de los strambotti de Olympo Sassoferrato, pero que él prefier llamar blasón, con el que invitaba a los poetas franceses a descubrir el cuerpo femenino, enseñándoles a dividirlo, como señala Albert Marie Schmidt, "en maites délicieuses merveilles" (1950, 73 ).

El entusiasmo que despertó este blasón en Francia fue enorme y la respuesta a la llamada provocativa de Marot inmediata, pudiendóse afirmar que pocos poetas escaparon a la práctica de esta modalidad poética, que se presentaba en esos momentos como una novedad, pero que no era, sin embargo, totalmente desconocida en la literatura francesa.

Porque, en efecto, si bien es la poesía italiana la que anima a Marot a blasonar el cuerpo femenino, los antecedentes de este arte no faltan en Francia donde asistimos a todo lo largo de la Edad Media, pero sobre todo en los siglos XIV y XV, a una cultura del blasón y del arte de blasonar, estrechamente vinculados a la emblemática, en la que blasón y blasonar pasan de tener una significación puramente heráldica, de descripción e interpretación del escudo de armas de un reino, una ciudad o una familia, a hacerse extensiva a otros campos: personas, animales, objetos e incluso conceptos abstractos, convirtiéndose en un juego literario de descripción en forma de alabanza o vituperio. Así, encontramos blasones de los animales domésticos, de las ciudades, de los oficios, del vino, etc. Se blasonan de forma paródica y satírica los procesos judiciales, algunas 
enfermedades características de la época y, más especialmente, a las mujeres, siempre con relación a alguna ciudad importante como París, Lyon o Rouen. Pero el blasón como forma literaria tendría sus antecedentes más lejanos, toda la crítica especializada coincide en ello, en los Dits y Debats medievales, en los bestiarios y catálogos de plantas, e incluso en los exemplum de la casuística. Aunque los precursores más cercanos hay que buscarlos en el siglo XV, en los más explícitos Blasons des Faulses amours de Guillaume Alexis y en los blasones licenciosos y procaces de Monsieur le Cul y de Les barbes de maintenant, de Coquillard y de Pierre Gringore.También se ha visto otros precedentes más inmediatos en composiciones poéticas que han sido consideradas como pre-blasones: Le Miroir des Dames, de Jean Castel o Les Regrets de la Belle Haulmière, de François Villon. Y, por último, la obra de los Rhétoriqueurs abunda en esta forma literaria que no cobra, sin embargo, el valor de auténtico género poético hasta pasado el primer tercio del siglo XVI, con los Blasones anatómicos del cuerpo femenino que inicia Marot.

Con todos estos precedentes y volviendo a la Francia de Francisco $\mathrm{I}^{\circ}$, lo cierto es que la fiebre que provoca el Beau Tetin de Marot desencadena un proceso de desnudamiento, de fragmentación del cuerpo femenino a través del poema, convertido gracias a la mirada exploratoria y furtiva del poeta, que se hace voyeur, en puro espacio de la evocación y del deseo. De esta manera, con el blasón, el cuerpo cobra una dimensión erótica como no había tenido hasta entonces en la literatura francesa, se fetichiza y cada una de las partes que se blasonan se convierten, por un proceso de metonimización, en el propio Cuerpo, con mayúscula, de la mujer.

Desde Los cabellos de Jean Vauzelles, hasta El pie de François Sagon, pasando por El culo de Eustorg de Beaulieu o el anónimo del Coño, se blasonan todas esas merveilles de la femme que inspirarán, con miradas diversas, la poesía del Renacimiento en Francia.

Pero no sólo el culto de la belleza femenina mueve el ejercicio blasonador. Una reacción de protesta puritana y también de resentimiento por el éxito de los blasones, movida, fundamentalmente, por los enemigos de Marot, provoca la aparición de contrablasones, que denigran las partes del cuerpo alabadas. Los principales animadores de esta reacción fueron Gilles Corrozet, uno de los principales opositores a la corriente blasonadora, que compuso un Blasón contra los blasonadores de los miembros, y Charles de la Hueterie, autor de la mayoría de los contrablasones conocidos. El propio Marot, preocupado por las proporciones escandalosas que tomaba el asunto, se vio empujado a componer su Contreblason du Laid Tetin y a lanzar una llamada a la moderación, en forma de epístola, a todos los poetas blasonadores. En este clima de hostilidad otro ilustre poeta blasonador, Eustorg de Beaulieu, que se hizo padre reformista, se arrepintió públicamente y compuso un Blasón espiritual de alabanza al muy digno cuerpo 
de Jesucristo, después de confesarse autor de siete blasones lúbricos, entre ellos, La mejilla, La lengua, El culo y El pedo.

Los blasones y contrablasones conocidos suman en total, más de cuarenta composiciones poéticas de muy desigual extensión y notables diferencias de tono y estilo, como corresponde a una obra colectiva que reúne sensibilidades poéticas muy diversas y objetivos a veces contrapuestos. Una producción poética que ha llegado hasta nosotros atravesando no pocas dificultades y no siempre en las mejores condiciones de edición y de fiabilidad. Sobre la recepción y fortuna de esta poesía a lo largo de la historia creemos necesario aportar algunos datos.

No parece cuestionable el éxito que los blasones tuvieron en su tiempo, a juzgar por las ediciones que se hicieron y de las que sólo tenemos noticias por los catálogos de los libreros, los "Infiernos" de las bibliotecas y las colecciones privadas. Pero llama poderosamente la atención el hecho de que toda la producción de blasones y contrablasones anatómicos haya tenido lugar en un período de tiempo extremadamente corto, que va de 1535 a 1542 aproximadamente. A partir de esa fecha el género desaparecerá de la escena literaria francesa, donde no volverá a utilizarse más el término blasón para referirse a una composición poética laudatoria del cuerpo femenino, aunque seguirán apareciendo, de manera esporádica blasones de flores, animales y objetos de uso diverso. La llegada de la Pléiade y el desprestigio que sufrieron por el carácter lúbrico y escatológico de la mayoría de ellos puede explicar, en parte, su carácter efímero y su calificación de moda pasajera que moriría con Marot. Pero lo cierto es que si bien el género como tal dejó de existir a mediados del siglo XVI, el placer de blasonar el cuerpo femenino no desaparecerá por ello de la poesía francesa de la época y su presencia se dejará sentir en la obra de muchos poetas de la segunda mitad del siglo XVI, entre ellos Ronsard y Du Bellay, que no pudieron escapar a su influencia. Luego, tendremos que esperar hasta el siglo XX para que retorne un cierto espíritu blasonneur en la poesía francesa y encontremos en poetas como Paul Eluard o Louis Aragon formas poéticas que nos recuerdan a los blasones. Así nos explicamos los problemas de recepción y las dificultades de edición de una poesía que durante siglos ha permanecido recluida en los estantes de algunas colecciones privadas o en los "infiernos" de las bibliotecas y sólo la curiosidad de bibliófilos y de unos cuantos especialistas ha permitido, en los últimos decenios del siglo $\mathrm{XX}$, un cierto proceso de recuperación que la ha devuelto, en cierto modo, a la historia de la literatura, y la ha puesto al alcance de un público lector bastante menos restringido.

Los primeros blasones aparecen publicados en París, en 1536, bajo el título de Les fleurs de poésie françoise, formando parte, como apéndice, de la Hecatonphile de Léon-Baptiste de Alberti. De esta manera conocieron dos reediciones más en 1539. Pero, todo hace suponer la existencia de una primera edición separada de los blasones, hecha en Lyon en 1536, por el editor de Marot, 
François Juste, que habría supervisado el propio poeta. El autor del Manuel du Libraire, Paul Lacroix, (1880) menciona no menos de cuatro reediciones de esta primera de 1936, aunque parece que en ellas intervino Charles de la Hueterie, el enemigo de Marot, quien las modificaría y aumentaría significativamente. Aunque la primera edición conocida, que ha llegado hasta nosotros, considerada por muchos la más fiable, sigue siendo la de Charles Langelier, que se publica en París en 1550, con este largo título en el que por primera vez aparecen juntos blasones y contrablasones: $S$ 'en suivent les blasons anatomiques du corps féminin ensemble les contreblasons. De nouveau composez et aditionez, avec les figures, le tout mis par ordre, composez par plusieurs poetes contemporains, avec la table desdictz blasons et contre-blasons imprimez en cette année. La siguiente edición que ha llegado hasta nosotros es la de Bonfonfs, de la que la Biblioteca Nacional conserva un volumen (Enfer 600): Les blasons et contre blasons du corps masculin, et feminin. Composez par plusieurs Poetes avec les figures au plus pres du naturel, A Paris par la veuve de Jean Bonfons, demeurant en la rue neuve de nostre Dame, a l'enseigne Sainct Nicolas. Aparece sin fecha, aunque lo más probable es que sea de 1560. Esta edición, que sigue la de Langelier, es la más consultada sin duda, aunque aparece incompleta y resulta bastante difícil de leer debido a los numerosos errores tipográficos. Luego, tendremos que esperar hasta el siglo XIX para que los blasones sean de nuevo reeditados, aunque de manera incompleta, por el bibliófilo D. M. Méon en una recopilación que titula: Blasons. Poésies anciennes des XV et XVIème siècle. Écrites de différents auteurs imprimés et manuscrits. Par M.D.M.M.***. Augmentée d'un glossaire des mots hors d'usage. Paris, chez Guillemot, Librerie rue de Cléry, 1809. Y ya en el en el siglo XX, en 1907, la Bibliothèque Internationale d'Edition E. Sansot et Cie. Editeurs, en su Collection Erotica Selecta, publica en París, bajo la dirección del bibliófilo $\mathrm{Ad}^{* * *} \mathrm{~B}^{* * *}$ : Blasons anatomiques du corps fémimin. También de autor anónimo, aunque parece ser Bertrand Guegan, encontramos, en 1931 otra rara edición parisina: Blasons Anatomiques du corps féminin (sic). Publiés par le Bibliophile B.G. et imprimés par les Paralleles. Mucho más modernas y dirigidas a un público menos restringido son las ediciones de Jean Clarence Lambert, de 1963: Les blasons du corps féminin, que aparece con ilustraciones de la Escuela de Fontainebleau, publicada en Paris, en el Club de Livraires de France, Y la última, hasta la fecha, de 1982, es la de la Editorial Gallimard: Blasons anatomiques du corps féminin, suivis des Contreblasons, prologada por Pascal Laîné y comentada por Pascal Quignard. Se trata de una edición muy cuidada, que reproduce, para los blasones, la recopilación que aparece en la Hecatonphile de 1539 y la edición de Charles Langelier, para los contrablasones.

Pero, la verdadera recuperación y, de alguna manera, rehabilitación del género en el siglo $\mathrm{XX}$ se la debemos a Albert-Marie Schmidt, gracias a su conocido estudio: Poètes du XVIème siècle (1950), donde consagra un 
interesante capitulo a esta forma poética. Schmidt presenta en este trabajo una cuidada y muy completa antología de los blasones anatómicos, aunque no incluye los contrablasones, precedida de un incisivo estudio crítico, bastante revelador, $\mathrm{y}$ acompañada de una breve reseña biográfica de cada poeta "blasonneur". Ésta, de alguna manera salida de la clandestinidad de los blasones, supo despertar enseguida un interés renovado de críticos e historiadores que en los últimos años se ha puesto de manifiesto por la definitiva inclusión del género no sólo en historias de la poesía francesa (R. Sabatier, 1975), sino también en en los manuales de uso escolar (X. D'Arcos, 1984), que le han dedicado algunas páginas.

En lo referente a la técnica y procedimientos de composición el blasón reúne una serie de rasgos esenciales de los que Thomas Sevillet, el primer estudioso y teorizador de este género, nos informa con una definición que ha servido de referencia a todos los historiadores e investigadores modernos que se han acercado a esta forma poética:

"Le blason est une perpétuéle louenge ou continu vitupère de ce qu'on s'est proposé blasonner. Pource serviront bien celuy qui le voudra faire, tous lés lieus de demonstration escrits par les rheteurs Grecz et Latins. Je dy en l'une et en l'autre partie de louenge et de vitupère. Car autant bien se blasonne le laid comme le beau, et le mauvais comme le bon: tesmoin Marot et sés Blasons du beau et du laid Tetin: et sortent lés deus d'une mesme source, comme louenges et invectives. (...) Et comme le paintre et le Pöéte sont cousins germains, par la régle: Pictoribus atque poetis etc., me faudroit peu pousser pour croire que le Blason dés couleurs aus Armoiries, nous eut esté origine de peindre en Pöésie notre Blason. De quelconque coin soit-il sorty, le plus bref est le meilleur mesme il soit agu en conclusion: et est plus dous en ryme platte, en vers de huit syllabes: encores que ceus de dis n'en soient pas regettés comme ineptes" (1548).

Más que de una simple definición se trata de una auténtica proclama poética o manifiesto antes de que la Deffense et Illustration de la Langue françoyse, de Du Bellay, en 1549, se convirtiera en el programa poético de $L a$ Pléyade. El tratado de Sebillet fija, en efecto, el género y regula su uso, al mismo tiempo que nos revela, de acuerdo con Schmidt, sus cuatro rasgos esenciales: descripción de alabanza o vituperio, desarrollo relativamente breve, cadena de encantamientos propia de una letanía y tendencia a la objetividad $(1954,293)$.

Pero, nos parece también muy significativo la vinculación que establece el tratadista de la forma descriptiva del blasón con la pintura, así como el hincapié en el carácter puramente retórico del arte de blasonar. Porque el blasón se presenta, sobre todo, como juego de artificio verbal por el que se integra en esa constante lúdica y formalista, regida por la "contrainte", que atraviesa una gran 
parte de la poesía francesa desde los Rhétoriqueurs, a finales de la Edad Media, hasta el OULIPO, en la segunda mitad del siglo XX.

Ya sea de alabanza o vituperio, en el tipo de blasón que nos ocupa, se trata siempre de poesía del cuerpo femenino, que reposa, en efecto, en un sentimiento agudo de la lengua y en una preocupación descriptiva, que revela la pasión por la clasificación y el inventario. De esta manera, los blasones que aparecen en Francia entre 1535 y 1545 gracias al estímulo de Marot, responden, mucho más que a un deseo de imitación de la poesía italiana del momento, a una tradición humanista y pedagógica, de espíritu emblemático y catalográfico, que se remonta a la época medieval y se verá reflejada a todo lo largo del siglo XVI y la primera mitad del XVII. Así, una parte importante de la llamada poesía cientifica en el Renacimiento responde a este espíritu, al igual que los blasones de los objetos y animales que presenta Remy Belleau en sus Petites Inventions (15541556) o ya, en el primer tercio del siglo XVII, L'Essai des Merveilles de Etienne Binet (1621).

En todos estos casos se trata de ensalzar y celebrar las cosas de la naturaleza guiados por un criterio de selección que se basa en la idea de "maravilla". Y es precisamente esta idea, la mujer como maravilla del mundo, la que rige en el arte de blasonar el cuerpo femenino.

$Y$ este entusiasmo por el cuerpo de la mujer, conviene señalarlo, es el mismo que, de acuerdo con Pierre Laurens (1981, 65-80), impulsa a Binet y Léon Richeone en Francia, y a Fray Luis de Granada, en España, a ensalzar las cosas de la naturaleza como suprema manifestación del poder del Creador. Sólo que los poetas del cuerpo femenino optan por una corriente sensualista que no se opone, sino que es complementaria, a esa otra espiritualista de los "blasonadores" de las cosas de la naturaleza.

En este sentido, podemos decir que el blasón comparte, en cierto modo, esa noción de la escritura, que domina en el Renacimiento, a la que se refiere Laurens, haciendo referencia al Thrésor de l'Histoire des langues (1619) de Claude Duret:

\footnotetext{
“Toute la nature n'est qu'un chiffre et secrète écriture du grand oeuvre et essence de Dieu et de ses merveilles... Les lettres et écritures doivent à cause de ce que dessus être principalement employées pour honorer et servir Dieu, pour la sainte médiation de sa loy et nous représenter à l'entendement de ses merveilles" $(1981,73)$.
}

Lo que permite, según Laurens, subrayar la convergencia entre una teología del verbo y del lenguaje humano y el hedonismo pictórico, el placer de describir, tan sensible en los escritores de esta época. Hedonismo pictórico, que 
hace del blasón una mirada privilegiada del cuerpo femenino a través de la cual, como señala acertadamente Schmidt:

"il le captive, il s'en saisit, il l'enserre, il le ligote peu à peu dans les mailles d'un filet d'or, aux timbres purs, qui devient son secours métaphysique, sa cage perpetuelle, sa défense contre le temps" (1950, 73).

Ahora bien, esta manera de captación del cuerpo reposa en una técnica pictórica utilizada por los poetas manieristas, que Gisèle Matieu-Castellani denomina del "portrait-mosaïque":

"Un portrait tout fait de rondeurs et ignorant de la ligne droite, la linéature, comme ils ignorent l'immobilité et le repos" $(1987,22)$.

Para Mathieu-Castellani, el cuerpo femenino manierista, que es el de los poetas blasonneurs, se divide en partes autónomas: el rostro, el cuerpo, los miembros y se subdivide en elementos discontinuos: el seno, el ojo, la ceja... etc., sin que se pueda hablar de un conjunto equilibrado por la harmonía de un todo, ni de visión global, ni de una jerarquía entre las diversas partes:

"Une tension extrème anime le portrait et détruit sa cohérence, tandis que chaque partie de ce corps, chaque élément de ce visage, se met à vivre d'une existence autonome, chacun séparément appelant un désir, promettant un plasir.Le portrait maniériste est plus pictural que linéaire: il ne tente plus de cerner les traits ni de définir les contours, mais d'en apporter l'équivalent émotionnel. C'est à dire que le poète vise moins à contempler et à faire contempler ce beau corps saisi en mouvement, qu'à provoquer une émotion toute charnelle.Une telle peinture est toujours érotique, tant est forte sa charge sensuelle, et sa fin n'est pas de donner à voir, mais de faire naître et d'entretenir le désir $(1987,23)$.

Y para lograr esa pintura erótica los poetas blasonneurs utilizan una serie de procedimientos retóricos que repasaremos brevemente. El blasón, según lo define Sebillet requiere, en cuanto a su forma estrófica, versos pareados octosílabos, aunque los decasílabos no sean despreciables, como lo demuestra el que dedica Scève a la ceja, uno de los más hermosos, aquí traducido, que terminará, a la postre, imponiéndose como modelo. Efectivamente, más de la mitad de los blasones y contrablasones utilizan el dizain francés. En algunos casos se combinan octosílabos y decasílabos.

La brevedad ha de ser.otra de las normas a seguir, como exige el carácter epigramático del blasón, pero casi nunca se cumple esta premisa pues nos 
encontramos con composiciones cuya extensión varía entre los dieciocho versos de La frente, de Maurice Scève, y los ciento diecinueve del Pie, de François Sagon, superando casi todos los treinta.

El eslabón que articula la estructura estrófica es la anáfora inicial de muchos de los versos. El recurso anafórico parece responder a la imposibilidad de hacer una descripción elogiosa completa y original por parte del poeta de la parte del cuerpo en cuestión. Tras un proceso acumulativo de elogios o negación de defectos, que exigen constanternente volver a empezar, se llega, por fin, a la queja de amor, a la súplica o a la expresión del deseo inalcanzable. Sobre los inconvenientes del procedimiento anafórico, el principal recurso del género, y los cambios que introducen los poetas blasonneurs para evitar la monotonía que inevitablemente provoca, resulta interesante el estudio de Kacimierz Kupisz (1972, 67-88). La figura retórica del apóstrofe está, por otra parte, presente en todos los blasones. Esta construcción apostrófica que en principio constituía un recurso más del carácter descriptivo del blasón y se presentaba habitualmente en forma de petición para cerrar la descripción laudativa, evoluciona hasta convertirse en una enunciacion personal que convierte el blasón en lugar de la efusión lírica gracias a esa petición final que constituye, de acuerdo con Kazimierz Kupisz,

"le dernier chaînon d'une apostrophe que la première invocation a déjà introduite et les invocations qui se déroulaient après, indépendament de la longueur, continuaient à marquer" (1972: 74).

El poeta se dirige directamente a la parte del cuerpo a elogiar, individualizándola y personificándola para, más que describirla, justificar su elección, dar cuenta de sus experiencias personales y liberar sus deseos.

En cuanto al léxico, Marot en su épitre dedicado a ceulx qui, après l'épigrame du Beau Tétin, en feirent d'autres (1536), advierte:
...mas os ruego que cada "blasonneur"
se cuide en sus escritos de emplear
palabras malsonantes o groseras;
Hablemos solamente de los miembros
que descubrirse pueden sin vergüenza;
no manchemos con los otros nuestros versos,
pues ¿qué razón de sacar a la luz
lo que natura celosamente guarda?

Una advertencia que cayó en saco roto y que sólo sirvió para poner de manifiesto la existencia de una verdadera querella literaria en torno a los blasones y para provocar la aparición de los contrablasones, que, como se sabe, suscitaronn 
la indignación de las damas y el descrédito de cuantas composiciones les sucedieron. Blasones y contrablasones obedecen, ya lo hemos dicho, a sensibilidades muy distintas y a influencias diversas que se reflejan perfectamente tanto en el tono y el registro léxico, como en la estructuración temática. De acuerdo con estas diferencias se han establecido hasta cuatro tipos diferentes, que nosotros por razones prácticas vamos a simplificar en dos grandes grupos.

El primero lo integrarían los de "estilo grivois", caracterizado por un tono más o menos grosero e indecente que hace de este tipo de blasón el más representativo, sin duda, del género poético. El estilo grivois, de inspiración y tradición medievales, se caracteriza por el uso y abuso de términos "malsonantes" y escatológicos tendentes bien a ridiculizar la fealdad natural del cuerpo, bien a resaltar con humor los atributos de la dama, pero dejando siempre patente, como dice Octavio Paz, una forma de "nombrar con naturalidad las cosas" (1971:41). A este estilo pertenecen, sobre todo, los contrablasones aunque también participan de él algunos blasones de las partes más recatadas del cuerpo femenino. Piénsese en los dedicados al Culo, el Coño o al Beau Tétin, donde lo grivois sólo se manifiesta en la gracia y sensualidad de un lenguaje que pone de relieve, en palabras de Paz, la lozanía y riqueza de una lengua mucho más desinhibida y terrestre que la de nuestro tiempo (1971: 41).

El segundo estaría formado por los de "estilo petrarquista". El estilo de estos blasones resulta tan fácilmente identificable que pasaremos por alto una descripción pormenorizada. En ellos, el tono cortés y la tradición petrarquista se conjugan para articular una temática bien conocida: la del caballero servidor de la dama, el mal de amor, la mujer como bien inalcanzable, la crueldad de la amada etc. Todos estos temas recurrentes de la poética del amor cortés y petrarquista se vehiculan a través de la descripción de la parte del cuerpo blasonada, mediante un proceso de metaforización que convierte el miembro escogido en el lugar de la efusión lírica. Los blasones de Maurice Scève a $L a$ Ceja a La Lágrima y al Suspiro son los más representativos de este estilo en el que no cabe, como es lógico suponer, la forma del contrablasón.

Hemos escogido para nuestra traducción tres blasones y un contrablasón que ilustran perfectamente estos dos estilos. Para ello hemos elegido los dos poemas de Marot, su blason del Beau Tétin y del Laid Tétin, quizás los más representativos del tono grivois y los blasones de Le sourcil, de Maurice Scève y de L'oeil, de Antoine Heroet, dos máximos exponentes del estilo petrarquista. En ellos se aprecia no sólo las características formales que fijan el género sino también la evolución y las variantes que lo enriquecen en el corto trayecto de su vida.

Entrando ya en nuestra práctica traductora hemos escogido la forma versificada que, a nuestro juicio, mejor se adapta en castellano a este tipo de poemas, es decir el endecasílabo, siguiendo la mejor tradición que Quevedo 
impusiera en sus Poemas satíricos y burlescos, pero también porque es el metro que se corresponde mejor, desde el punto de vista cultural, con las nuevas formas poéticas que en Francia aclimata el dizain.

En el aspecto musical y rítmico, las rimas fortuitas no han sido evitadas, si con ello contribuían, según nuestro criterio, a prestar al nuevo poema algo de la sonoridad del original, inevitablemente perdida en toda traducción. Ninguna de las existentes, sin embargo, ha sido deliberadamente forzada o llevada más allá de las coincidencias naturales en los dos idiomas; con ello salvaguardamos el sentido. Así, en el pareado final de El bello seno con doncella/bella o en el de La teta fea con fea / babea. La consonancia final envite / vomite en este poema busca un efecto sonoro contundente que lo cierre. Forzar el orden versal al objeto de obtener un pareado nos parecía excesivo; tal licencia añade, creemos, un tono irónicocómico acorde con el que caracteriza el poema.

En el blason de l'oeil, sobradas razones tanto de estilo como de índole connotativo nos han aconsejado el plural ojos en la traducción, decisión ésta avalada por Góngora - Divinos ojos, que en su dulce oriente.. o Gutierre de Cetina - Ojos claros, serenos...

\section{LE BEAU TETIN}

Tetin refaict, plus blanc qu'un oeuf

Tetin de satin blanc tout neuf,

Tetin qui fais honte à la Rose,

Tetin plus beau que nulle chose,

Tetin dur, non pas tetin, voyre,

Masi petite boule d'ivoire,

Au milieu duquel est assise

Une Freze, ou une Cerise

Que nul ne veoit, ne touche aussi

Mais je gage qu'il est ainsi:

Tetin donc au petit bout rouge,

Tetin qui jamais ne se bouge,

Soit pour venir, soit pour aller,

Soit pour courir, soit pour baller:

Tetin gauche tetin mignon,

Toujours loin de son compagnon,

Tetin qui portes tesmoignage

Du demourant du personage,

Quand on te voit, il vient à maintz

Une envie dedans les mains

De te taster, de te tenir: 
Mais il se fault bien contenir

D'en approcher, bon gré ma vie,

Car il viendroit une autre envie.

$\mathrm{O}$ tetin ne grand, ne petit,

Tetin meur, tetin d'appetit,

Tetin qui nuict et jour criez:

Mariez moy tost, mariez!

Tetin qui t'enfles, et repoulses,

Ton gorgias de deux bons poulses,

A bon droict heureux on dira

Celluy qui de laict t'emplira,

Faisant d'un Tetin de pucelle

Tetin de femme entière et belle.

Clément Marot Épigrammes (1535)

\section{EL BELLO SENO}

Seno en sazón, de blanco nacarado, seno de satén blanco, fresco y nuevo, seno que ruborizas a la Rosa, seno al que nada iguala en hermosura, seno duro, que mucho más que a seno de marfil a una bola te asemejas, en cuyo centro con primor se asienta una rosada fresa, una cereza, que nadie puede ver ni tocar puede, mas que así es apuesto cualquier cosa. Seno, en fin, con una puntilla roja, seno tan firme que jamás te mueves, tanto da que tu dueña vaya o venga tanto da que tu dueña baile o corra. Seno izquierdo, maravilloso seno, siempre alejado de tu compañero, seno que eres el vivo testimonio de los otros tesoros de tu dueña. Al verte pocos son los que no sienten en sus manos deseo irresistible de, al momento, tocarte y poseerte, mas preciso es, sin duda, refrenarse $y$ tenerse alejado, mal que pese, pues un deseo mayor provocaría. ¡Oh seno, ni grande ni pequeño, 
seno maduro, seno apetitoso, seno que vas gritando noche y día: ¡Desposadme, al pronto desposadme! Seno que te hinchas y haces que tu escote de dos buenas pulgadas se adelante. Se llamaría dichoso con justicia a aquel que a ti de leche te llenara y convirtiera ese seno de doncella en ux́ seno de mujer entera y bella.

LE SOURCIL

Sourcil traictif en vouste fleschissant Trop plus qu'hebene, ou jayet noircissant, Hault forgetté pour umbrager les yeulx, Quand ils font signe, ou de mort ou de mieulx. Sourcil qui rend paoureux les plus hardis, Et courageux les plus accouardis.

Sourcil qui fait l'air clair, obscur soubdain Quand il froncist par yre, ou par desdain, Et puis le rend serain, clair et joyeux Quand il est doux, plaisant et gracieux. Sourcil qui chasse et provoque les nues Selon que sont ses archées tenues. Sourcil assis au lieu hault pour enseigne Pour qui le cueur son vouloir nous enseigne Nous descouvrant sa profonde pensée: Ou soit de pax, ou de guerre offencée. Sourcil, non pas sourcil, mais ung soubz ciel Qui est le dixiesme et superficiel, Oủ lon peult veoir deux estoilles ardentes, Lesquelles sont de son arc dependentes, Estincellantz plus souvent et plus clair Qu'en esté chault ung bien soubdain esclair. Sourcil qui faict mon espoir prosperer, Et tout acoup me fait desesperer.

Sourcil sur qui amour print le pourtraict Et le patron de son arc, qui attraict Hommes et Dieux à son obeissance, Par triste mort ou doulce jouyssance. O sourcil brun soubz tes noires tenebres J'ensepvely en desirs trop funebres 
Ma liberté et ma doulente vie, Qui doulcement par toy me fust ravie.

Maurice Scève (1535)

\section{LA CEIA}

Ceja atrayente, en bóveda arqueada, aun más negra que el ébano y el jaspe, saliente que los ojos ensombrece para ocultar ya el duelo ya el contento. Ceja que hace cobarde al más osado y torna en valeroso al retraído.

Ceja que oscuro vuelve el aire claro cuando por ira o por desdén se frunce, y lo vuelve sereno, alegre y limpio cuando se muestra suave y agradable. Ceja que atrae y ahuyenta nubarrones según curve la línea de sus arcos. Ceja asentada en alto como enseña; donde el alma su voluntad nos muestra y nos descubre su hondo pensamiento por la paz ofendido o por la guerra. Ceja, ¡qué digo ceja!, es otro cielo, el décimo y de todos el somero, donde se ven dos ardientes estrellas cada cual de su arco dependiente, con resplandor más abundante y claro que el súbito relámpago en estío . Ceja que hace que crezcan mis anhelos y enseguida me lleva al desespero. Ceja de la que Amor copió el modelo para curva de su arco, que somete a sus dictados a dioses y hombres, ya sea por triste muerte o dulce gozo. Ceja bruna, tus oscuras tinieblas sepultan entre fúnebres deseos mi libertad y mi doliente vida por ti tan dulcemente arrebatada. 


\section{LE LAID TETIN}

Tetin, qui n'a rien que la peau, Tetin flat, tetin de drappeau, Grande tetine, longue tetasse, Tetin, dosi-je dire bezasse? Tetin au grand villain bout noir comme celüy d'un entonnoir, tetin qui brimballe à tous coups sans estre esbranlé ne secoux, bien se peult vanter qui te taste d'avoir mis la main à la paste! Tetin grillé, tetin pendant, Tetin flaitry, tetin rendant Vilaine bourbe en lieu de laict, Le diable te feit bien si laid.

Tetin pour trippe reputé, Tetin ce cuyde-je emprunté Ou desrobé en quelque sorte De quelque vieille chievre morte. Tetin propre pour en enfer Nourrir les enfants de lucifer. Tetin, boyau long d'une gaule, Tetasse à jecter sur l'espaule Pour faire, tout bien compassé, Un chaperon du temps passé. Quand on te voit, il vient à maintz Une envie dedans les mainz De te prendre avec gand doubles Pour en donnez cinq ou six couples De souffletz sur le nęz de celle Qui te cache soubz son esselle! $\mathrm{Va}$, grand vilain tetin puant, Tu fournirois bien, en suant, De civette et de parfuns Pour faire cent mille defunctz. Tetin de laideur despiteuse, Tetin dont nature est honteuse, Tetin des villains le plus brave, Tetin dont le bout tousjours bave, 
Tetin faict de poix et de glus.

Brief, ma plume, n'en parle plus, Laissez le là, ventre sainct george,

Vous me feriez rendre ma gorge!

Clément Marot (1536)

\section{LA TETA FEA}

Teta sin otra cosa que el pellejo, teta flaca, trapajo o parecido, ubre grande, teta dada de sí, teta, ¿mejor debo decir alforja?, teta en gran botón negro rematada que diríase la boca de un embudo, teta que al menor toque te meneas, sin que te agiten, sin que te sacudan. Bien puede presumir el que te toque de haber metido mano en una masa. Teta tostada , teta colgandera, teta ajada, teta vomitiva, cieno asqueroso en lugar de leche; el diablo no te pudo hacer más fea. Teta que eres por tripa reputada, teta, que más pareces ser prestada o Dios sabe a qué vieja cabra muerta de algún modo haber sido robada. Teta la propia para en el infierno amamantar al hijo del demonio. Teta, tripa del largo de una vara, tetaza para echársela a la espalda, y para hacer, con algo de maestría, una de esas antiguas caperuzas.

Al verte pocos son los que no sienten en sus manos deseos irresistibles de cogerte, pero con guantes dobles, y dar con ella cuatro o cinco pares de tetazos en la nariz de aquella que escondida te lleva en el sobaco. ¡Echa allá, horrible teta maloliente! Tu algalia y tu perfume cuando sudas para cien mil difuntos bastarían. 
Teta de la fealdad más despreciable, teta de toda la Creación vergüenza, teta de entre las feas la más fea, teta con esa punta que babea, teta a base de pez y liga hecha.¡Mierda, pluma, calla tras este envite! ¡Déjalo ahí, por los clavos de Cristo, o lograrás hacerme que vomite!

Clément Marot (1536)

BLASON DE L'OEIL

Oeil, non pas oeil, mais un soleil doré.

Oeil après Dieu de mes yeulx honnoré.

Oeil qui feroit de son assiete et taille

Durer dix ans encore une bataille.

Oeil me privant du regard qu'il me doit

Me voyant mieulx que s'il me regardoit.

Oeil sans lequel mon corps est inutile.

Oeil par lequel mon ame se distille.

Oeil, ô mon oeil disant: je te veux bien,

Puis que de toy vient mon mal et mon bien.

Oeil bel et net comme ciel azuré.

Oeil reposé, constant et asseuré.

Oeil qui ryroit, en me faisant mourir,

Qui pleureroit ne m'osant secourir.

Oeil de son faict luy mesmes esblouy.

Oeil qui diroit si sagement ouy:

Mais à qui oeil? À celluy que scavez.

Qui vous aura? Vous, celle qui mavez

Oeil qui pour rendre ung cueur de marbre uny

$\mathrm{Ne}$ daigneroit se monstrer qu'à demy.

Oeil s'accordant au ris de la fosette

Que faict amour en joue vermeillette.

Oeil où mon cueur s'estoit devant rendu,

Que luy eussies le logis deffendu.

Oeil si se veult tenir pensif et coy .

Qui fait sortir de soy je ne sçay quoy,

Que l'on veoit bien toutesfois commander

Aux demandeurs de riens ne demander.

Oeil qui me donne en y pensant tant d'ayse.

Oeil, ô doulx oeil que si souvent je baise: 
Voire mais, oeil, j'entendz que c'est en songe.

Oeil qui veoit bien qu'à luy me suys voué.

Oeil qui ne fut jamais assez loué.

Mais toutefois pour eviter envie,

Oeil doulx et beau, le propre de m'amye,

Oeil je suis vostre, et de ce vous asseure:

Escoutez moy mon oeil je vous conjure

Par Cupido que vous avez tout nud

Et par son arc qu'en vous ay recongneu,

Par le plaisir que l'ung des miens auroit

Si d'advanture à vous se mesuroit:

Par tout mon bien, à louverte fenestre,

Que vous voyez à mon costé senestre,

Par la beaulté de celle que scavez,

Par le venin que vous me reservez,

Oeil, dictes moy ce que vous respondictes,

Descouvrez moy le signe que me feistes

Quand on disoit que mal seroit assis

Le beau maintien de vostre esprit rassis,

Hors de la court s'il estoit entendu

En autre sens que ne l'avez rendu.

Declairez moy s'il vous plait ce langage

Et n'en parlez rien qu'à vostre adventage.

Antoine Heroet (1535)

BLASÓN A LOS OJOS

Ojos, mejor bellos soles dorados.

Ojos cual Dios honrados por mis ojos.

Ojos que harian por el lugar y talla

durar diez años más cualquier batalla.

Ojos que esquivan el mirar que anhelo

y me ven aun mejor que si me miran.

Ojos con cuya ausencia soy inútil.

Ojos por los que mi alma se sublima.

Ojos, jay, ojos!, que dicen: Te quiero,

pues de vosotros bien y mal me llegan.

Ojos como el azul limpios y bellos.

Ojos serenos, pertinaces, firmes.

Ojos que se reirían dándome muerte mas tras desampararme llorarían.

Ojos que de su acción se maravillan. 
Ojos que un sí darían con cordura:

Pero, ¿a quién, ojos? Ya sabéis a quién.

¿Quién os habrá? Tú, amada dueña mía.

Ojos que con mostrarse sólo a medias

un corazón de mármol rendirían.

Ojos acordes a ese hermoso hoyuelo

que encanta en tu mejilla sonrosada.

Ojos, ante vosotros mi alma rindo, aunque la tal morada le prohibieseis.

Ojos que despedís un no sé qué, cuando os queréis callados, pensativos, que se puede mandar de muy buen grado no pedir nada a los que pedir suelen.

Ojos cuyo recuerdo me sosiega.

Ojos que tanto beso, oh dulces ojos, aunque sea, ojos míos, sólo en sueños.

Ojos que no sufrís una mentira.

Ojos nunca demasiado alabados.

Mas para evitar cualquiera celo, ojos dulces y bellos de mi amada, ojos, soy todo vuestro, os lo aseguro:

Escuchadme, ojos míos, yo os conjuro, por Cupido, al que tenéis desnudo y por su arco que en vosotros he visto, por el placer que uno de los míos habría pareciéndose a los vuestros, por mi bien todo que, en la ventana abierta, podéis ver tan siniestro en esta hora, por la belleza de la que sabéis, por el veneno que me reserváis, ojos, decidme cuál fue la respuesta, reveladme los signos que me hicisteis cuando se dijo que no había motivo para tanto elogiar vuestro talento, si fuera de la corte se entendió algo distinto de lo que habéis dicho. Desveladme, si os place, ese secreto y nada digáis que dañaros pueda. 


\section{Bibliografía citada}

BINET, E., Essai des Merveilles de la Nature, et des plus nobles Artifices. Pièce très nécessaire à tous ceux qui font profession d'Eloquence. Par René François, Prédicateur du Roi, Rouen, 1621.

COSERIU, E., “Alcances y límites de la traducción”, Lexis, XXI/2 (1997), pp. 163-185.

FERNÁNDEZ, E., "Sola una de vuestras manos: Desmembramiento petrarquista y disección anatómica en la venta (Don Quijote,I, 43)". Doc. Internet, University of Manitoba, 2001.

JAKOBSON, R., "La dominante" en: Huit questions de poétique, Paris: Editions du Seuil, 1997.

KAZIMIERZ KÜPISZ, "Des recherches sur l'évolution du blason au XVIème siècle" Zagadnienia Rodzajów Literackich, 9/2 (1972).

LACROIX, P., Notices sur des livres rares et curieux...1880. Doc. Intenet, textes rares, 2002.

LAURENS, P., "Essai des Merveilles d'Etienne Binet" en: Automne de la Renaissance, 1580-1630. Etudes réunies par Jean Lafon et André Stegman. Paris: Vrin, 1981, pp. 65-80.

MATHIEU-CASTELLANI, G., Eros baroque, Paris: Nizet, 1987.

MOUNIN, G., Les problèmes théoriques de la traduction, Paris: Gallimard, 1963.

NIDA, E.A. y TABER, CH. R., La traducción: teoría y práctica. Madrid: Ediciones Cristiandad, 1986.

PAZ, O., Traducción literaria y literalidad, Barcelona: Tusquets, 1971.

SABATIER, R., Histoire de la poésie française. La poésie du seizième siècle.

Paris: Albin Michel, 1975.

SÁEZ DE HERMOSILLA, T., El sentido de la traducción, reflexión y critica.

Salamanca: Servicio de Publicaciones de la U. de León, 1994.

SEVILLET, T., Art Poëtique François pour l'instruction de jeunes studiens et encor peu avancéz en la Poesie Françoise, Edition de F. Gaiffe, Paris, 1910 (=Paris: Gilles Corrozet, 1548).

SCHMIDT, A.-M., Poètes du XVIème siècle, Paris: Gallimard, 1950.

TORRE, E., Teoria de la tradución literaria. Madrid: Editorial Síntesis, 1994. VINAY, J. P., Stylistique comparée du français et de l'anglais, Paris: Didier, 1958. 